\title{
Educational needs of foundation doctors caring for dying patients
}

\author{
GT Linklater \\ Consultant in Palliative Medicine, NHS Grampian, and Foundation Programme Director, North of Scotland Deanery, NHS Education Scotland, UK
}

\begin{abstract}
The aim of this study was to identify the educational needs of year one North of Scotland foundation doctors caring for dying patients. A postal questionnaire approach was used. The results from the questionnaire (79/132 respondents) confirmed that year one foundation doctors are frequently exposed to patient death, with $61 \%$ finding their most memorable patient death to be emotionally distressing. A quarter $(26 \%)$ of respondents had recent experience of significant personal bereavement. Communicating with patients and relatives at the end of life, concerns about overtreatment and lack of senior support were highlighted as particularly difficult issues. Educational needs of the foundation doctors were identified, emphasising the importance of emotional, analytical and personal competencies.
\end{abstract}

Correspondence to GT Linklater, Roxburghe House, Ashgrove Road, Aberdeen AB25 2ZH, UK

tel. +44 (0) I 224557057 e-mail g.linklater@nhs.net

KEYWORDS Competencies, death, junior doctors, support

DECLARATION OF INTERESTS No conflict of interests declared.

More than $50 \%$ of all deaths in the UK happen in acute hospitals. ${ }^{1,2}$ At any one time it is estimated that at least $12 \%$ of all hospital inpatients have 'advanced disease' (prognosis less than three months) and that up to $86 \%$ of all deaths follow a period of illness and/or frailty., In other words, most deaths are to some extent predictable. Yet many junior doctors find caring for the dying to be stressful: ${ }^{5-8}$

One of the most ill-starred meetings in modern medicine is that between a frail defenceless old man nearing the end of his life, and an agile young intern at the beginning of his career. ${ }^{9}$

Several aspects of caring for dying patients have been highlighted in the published literature as contributing to junior doctors' stress/distress. These doctors often feel unprepared for dealing with dying patients ${ }^{9-11}$ and find communicating with dying patients and their relatives particularly difficult., ${ }^{5,12,13}$ This can be heightened if the patient/relatives in some way remind the doctor of their own family ${ }^{12,14,15}$ or if the doctor has not had an opportunity to build up a relationship with them, e.g. when 'crosscovering'.,16 Overtreatment (real or perceived), 12,14,17,18 patient suffering ${ }^{15,19}$ and lack of support ${ }^{7,9,12,14}$ are all recognised as contributing to junior doctor distress, in particular causing feelings of guilt and self-blame..$^{14,20}$

Care of the dying has been recognised as important by the Scottish Government,' the General Medical Council ${ }^{21}$ and the Academy of Medical Royal Colleges (AMRC). ${ }^{22,23}$ The North of Scotland Deanery needed to respond to the requirements of the AMRC (2007) Foundation Programme curriculum document ${ }^{23}$ for all the foundation trainees in the region. The existing North of Scotland Foundation teaching programme did not have any sessions specifically about end-of-life care.
The aim of this study was to explore the experiences of junior doctors looking after dying patients, with a view to developing an educational intervention that would address any identified educational needs.

\section{TARGET POPULATION AND METHODS}

Year one foundation (FYI) doctors (i.e. in their first year after obtaining their medical degrees) working within the North of Scotland Deanery $(n=132)$ were chosen as the target population. It was felt that any educational intervention resulting from the needs assessment should be tailored for FYls because such an intervention would be 'too early' in medical school, where learners would have difficulty putting their learning in context. Year two would be 'too late' to address issues of junior doctors being unprepared and unsupported for the care of the dying task.

A postal questionnaire was chosen as the most appropriate method for several reasons: ${ }^{24,25}$

- It provided an opportunity for all FYI doctors in the region that would be affected by the educational intervention to share their views.

- By including the entire target population, it was hoped that ownership of any resulting educational programme would be promoted.

- The target population was spread over a very large geographical area (Grampian, Moray, Highlands, Orkney, Shetland and the Western Isles). A postal questionnaire was the only cheap and efficient means of reaching them all.

- A questionnaire provided the means of answering the research questions.

- Coding and analysis of the data would be achievable by the researcher. 
TABLE I Questionnaire on foundation year doctors' experiences of death and dying

I. How old are you?
$\square$ 20-24 $\square$ 25-29 $\square$ 30-34 $\square>35$

2. How long have you been working as a doctor? $\square<3$ months $\square$ 3-6 months $\square$ 6-12 months $\square>12$ months

3. Where are you working at present?

$\square$ General Medicine

$\square$ Care of the Elderly

$\square$ General Surgery

$\square$ Paediatrics

Obstetrics and Gynaecology

$\square$ General Practice

$\square$ Other (please specify).

4. Have you had any close family or friend bereavements in the last year? $\square$ Yes $\square$ No

5. How many patients have you been involved with at or around the time of death?

$\square$ None - please go to Q.7

$\square$ One - please go to $\mathrm{Q} .6$

$\square$ 2-5 - please go to Q.6

5-10 - please go to Q.6

$>10$ - please go to Q.6

6. Please consider the patient death you feel is the most memorable.

a) How long had you known the patient? $\square<1$ hour $\square \mathrm{I}-24$ hours $\square \mathrm{I}-7$ days $\square \mathrm{I}-4$ weeks
$\square$ Months

b) Was the death expected?

$\square$ Yes $\square$ No $\square$ Don't know

c) The patient had unrelieved suffering.

$\square$ Strongly disagree $\square$ Disagree $\square$ Agree $\square$ Strongly agree

d) The death had a strong emotional impact on you. $\square$ Strongly disagree $\square$ Disagree $\square$ Agree $\square$ Strongly agree

e) You received adequate support following the death. $\square$ Strongly disagree $\square$ Disagree $\square$ Agree $\square$ Strongly agree

Question development was informed by a literature review of junior doctors' experiences. The questionnaire (Table I) provided the opportunity to confirm/further explore the themes from the literature in the local setting, with a particular focus on the following questions:

- Is recent personal bereavement common?

- Is exposure to patient death frequent?

- Are patient deaths seen as emotionally powerful? Which factors contribute to this experience (brief relationship with the patient, unexpectedness, unrelieved suffering, lack of support)?

- How difficult are common tasks when caring for dying patients?

- Is perceived overtreatment an issue? Is perceived undertreatment an issue?

- Who do FYI doctors look to for support? How frequently is support received from senior medical staff?
7. Please rank the following situations according to how difficult you find them. (Circle appropriate response)

a) Talking to patients about death.

Not at all Most difficult situation possible

$\begin{array}{lllllllllll}0 & \mathrm{I} & 2 & 3 & 4 & 5 & 6 & 7 & 8 & 9 & 10\end{array}$

b) Talking to relatives about death.

Not at all Most difficult situation possible

$\begin{array}{lllllllllll}0 & 1 & 2 & 3 & 4 & 5 & 6 & 7 & 8 & 9 & 10\end{array}$

c) Certifying death.

Not at all Most difficult situation possible

$\begin{array}{lllllllllll}0 & 1 & 2 & 3 & 4 & 5 & 6 & 7 & 8 & 9 & 10\end{array}$

d) Viewing bodies in the mortuary.

Not at all Most difficult situation possible

$\begin{array}{lllllllllll}0 & \mathrm{I} & 2 & 3 & 4 & 5 & 6 & 7 & 8 & 9 & 10\end{array}$

e) Talking to recently bereaved relatives.

Not at all Most difficult situation possible

$\begin{array}{lllllllllll}0 & \mathrm{I} & 2 & 3 & 4 & 5 & 6 & 7 & 8 & 9 & 10\end{array}$

f) Please describe any other situations you find difficult.

8. Have you ever been uncomfortable with your consultant's decision to...

a) stop feeding/fluids $\square$ Yes $\square$ No

b) continue or commence feeding/fluids $\square$ Yes $\square$ No

c) sign a 'not for resuscitation' form $\square$ Yes $\square$ No

d) refuse to sign a 'not for resuscitation' form

$\square$ Yes $\square$ No

9. Have you ever had to sign a 'not for resuscitation' form without consultant or SpR supervision?

$\square$ Yes $\square$ No

10. Have you received support from any of the

following during or after a patient's terminal illness?

(Tick as many boxes as appropriate)

$\square$ Other foundation year doctors

Senior house officers/specialist registrars

Nurses

Consultant

Educational supervisor

Family

Friends

Other (please specify)

- Are FYI doctors signing 'not for resuscitation' forms without support/supervision? This question did not arise from the literature review. However, the author was aware of anecdotal reports of this practice happening locally.

The questionnaire was pilot-tested by junior doctors within the department of palliative medicine to ensure the questions were understood and considered relevant and acceptable. The questionnaires were posted to all I32 North of Scotland FYI doctors, with a covering letter assuring anonymity. A stamped, addressed envelope was enclosed.

Ethical review The North of Scotland Research Ethics Committee reviewed and approved the study. 


\section{RESULTS}

\section{Respondents}

A total of 74/I 32 (56\%) completed questionnaires were returned. Almost all the respondents were under 30 years old (7I/74 [96\%]) and had been working for between six and 12 months (72/74 [97\%]). They were working in a wide range of specialties (general medicine $n=19$, care of the elderly $n=10$, general surgery $n=23$, paediatrics $n=5$, obstetrics and gynaecology $n=5$, other $n=12)$. Just over a quarter (19/74 [26\%]) of respondents had a close family or friend bereavement in the last year. The majority (55/74 [74\%]) had been involved at least five times with patients at or around the time of death. Only one respondent stated that they had not been involved in the care of a patient at the end of life.

\section{Most memorable patient death}

The majority (53/74 [72\%]) of 'most memorable' patient deaths were expected. The FYI had known the patient for less than one week in 44/74 (59\%) cases; 5/74 (7\%) had known the patient for less than one hour. Most $(53 / 74$ [72\%]) did not feel their patient had unrelieved suffering (Figure I), but more than half (45/74 [6I\%]) felt the death had a strong emotional impact on them (Figure 2). Approximately half (4I/74 [55\%]) reported having adequate support following the death (Figure 3 ).

\section{How difficult are common tasks when caring for dying patients?}

Talking to patients about death, talking to relatives about death and talking to bereaved families were felt to be difficult (score $\geq 5 / 10$ ) for the majority of respondents (88\%, 82\%, 84\% respectively, median scores $7,7,7.5$ respectively). Certifying death or viewing bodies in the mortuary were perceived as easier tasks (median scores 2 and 3.5 respectively).

Particular difficulties around communicating at the end of life were described by some respondents in free text responses. Six respondents emphasised that discussing not for rescuscitation (NFR) forms and the withdrawal of active treatments were the aspects of speaking to relatives that they found most difficult. Other contributing factors that made communication difficult were not knowing the patient ('telling families that their relative had died when you are covering and don't properly know the patient'), and lack of senior support ('being left at a weekend to deal with palliative patients when my senior house officer is busy with other patients'). One respondent described a weekend when five patients died as 'the hardest 48 hours l've spent in medicine with no support from anyone'.

Other situations that were identified as difficult in the free text responses included getting all the necessary paperwork (death certificates, cremation forms) done ('after being shocked by patient's sudden death being

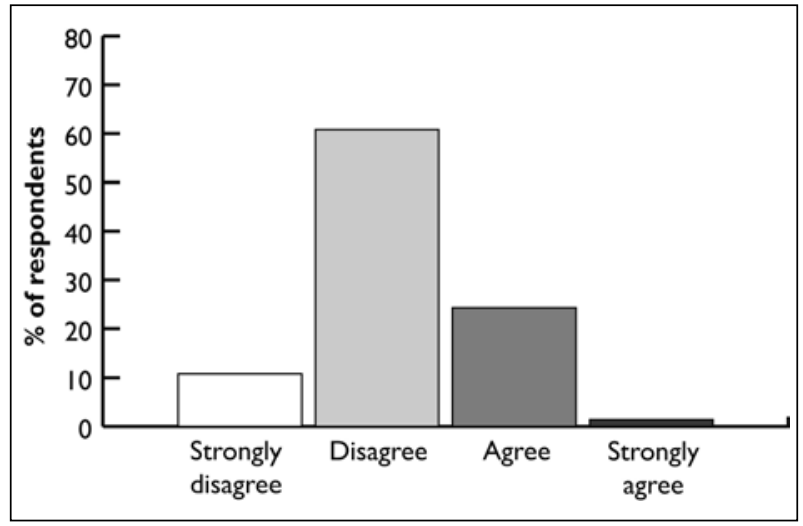

FIGURE I The patient had unrelieved suffering.

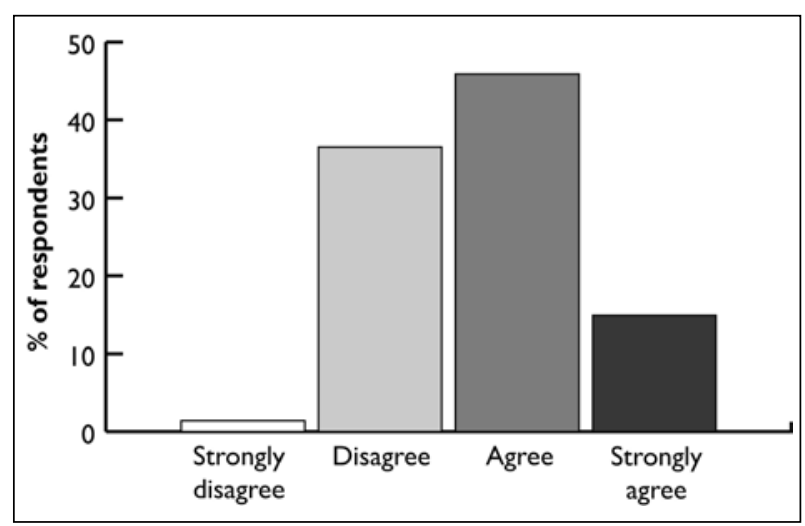

FIGURE 2 The death had a strong emotional impact on you.

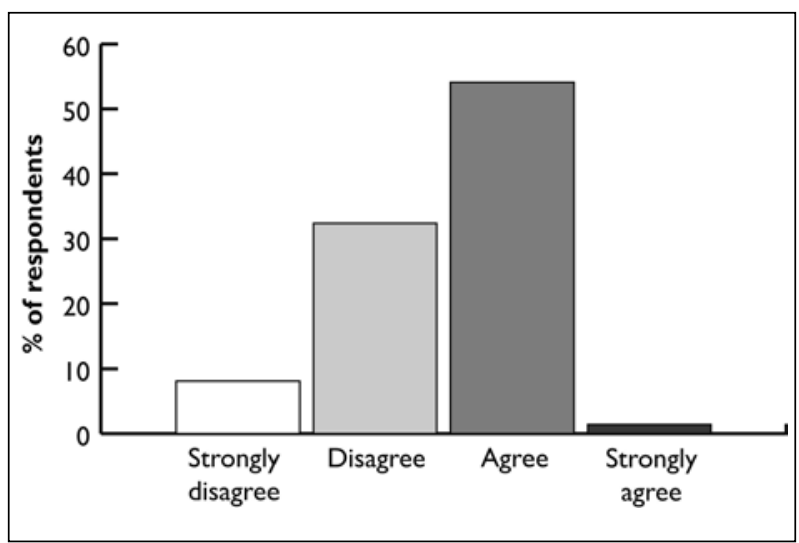

FIGURE 3 You received adequate support following the death.

harassed to get cremation papers done immediately'), supporting colleagues and coming to terms with one's own emotions. One respondent described 'difficult[y] accepting that someone can die despite everyone's best efforts'. Another reflected 'how a death [that] doesn't seem to affect some other doctors makes you question your ability.

\section{Is perceived overtreatment an issue?}

Two fifths of respondents had been uncomfortable with apparent 'overtreatment' decisions by consultants at the end of life - continuing fluids (30/74 [4I\%]) and refusing to sign an NFR form (30/74 [4I\%]). A smaller proportion 
TABLE 2 Sources of support for junior doctors following patient death

\begin{tabular}{|l|l|l|}
\hline Source of support & $\mathbf{n}$ & $\%$ \\
\hline Other FYI & 53 & 72 \\
\hline Nurse & 36 & 49 \\
\hline Friend & 28 & 38 \\
\hline Family & 27 & 36 \\
\hline Senior house officer/Specialty registrar & 24 & 32 \\
\hline Consultant & 6 & 8 \\
\hline Educational supervisor & 2 & 3 \\
\hline None & 11 & 15 \\
\hline
\end{tabular}

were concerned about perceived undertreatment discontinuing fluids (I6/74 [22\%]) and signing an NFR form $(8 / 74$ [II\%]).

\section{Are FYIs signing NFR forms without support?}

Almost one fifth (14/74 [19\%]) had had to sign an NFR form without senior doctor supervision.

\section{Who is accessed for support?}

The most common sources of support for FYI doctors were their fellow FYIs (53/74 [72\%]) and their nursing colleagues (36/74 [49\%]). Only 8/74 (1 I\%) respondents had received support from a consultant or educational supervisor. Some I I/74 (I5\%) respondents felt they had not received any support (Table 2 ).

\section{DISCUSSION}

The questionnaire confirmed that end-of-life care situations are experienced by North of Scotland FYI doctors. While $61 \%$ of respondents described their most memorable patient death as having a 'strong emotional impact', it is interesting to note that most of these deaths were not considered to be unexpected or associated with unrelieved suffering. This contrasts with previous research that identified strong emotions as being related to perceived suffering and the death being shocking or unexpected..$^{14,15}$ If deaths are not shocking or accompanied by suffering then why do they still cause distress?

It is conceivable that these junior doctors are struggling with the realisation that death is inevitable, and that the biomedical fight against disease is often unsuccessful. ${ }^{26} \mathrm{At}$ least $12 \%$ of patients in an acute hospital are in the terminal phase of their illness. ${ }^{4}$ This proportion of the workload is not reflected in the emphasis given to palliative and end-of-life care in undergraduate medical curricula (e.g. Aberdeen's undergraduate curriculum has just six days' focus on palliative/end-of-life care).

The questionnaire did, however, highlight other issues that may contribute to the care of the dying task being difficult for junior doctors. Just over a quarter of respondents had experienced a close family or friend bereavement in the previous year. The incidence of close family/friend bereavement for FYI doctors has not previously been published. There may have been response bias, with FYI doctors who had experienced recent bereavement being more likely to return their questionnaires. However, even if we assume that all nonrespondents did not have a recent bereavement we are still left with an incidence of recent bereavement of $14 \%$. Personal experience of loss and family illness have been described as qualitative themes important in emotionally powerful incidents. ${ }^{12,14}$

Communicating with patients or families around the time of death is well recognised as difficult and stressful. $5,12,16,27,28$ This is confirmed by the survey, which also highlights that these communication scenarios are considered more difficult than other potentially distressing duties of a junior doctor (specifically, certifying death and identifying bodies in the mortuary).

The literature also suggests that perceived overtreatment at the end of life is a source of stress for junior doctors. ${ }^{12,14,17,18,29}$ Respondents to this survey more frequently identified being uncomfortable with a consultant's decision to continue treatment as opposed to a consultant's decision to withhold/withdraw treatment. This may reflect that such decisions may seem more 'real' to the junior doctor, who has to physically do something to a patient rather than omitting to do something. The apparent unnecessary continuation of treatment can have other consequences. Junior doctors perceive the overtreatment of the terminally ill as a mark of consultant fallibility. ${ }^{18}$ Those junior doctors who perceived their consultants as being fallible were the most likely to have poor job/career satisfaction. ${ }^{18}$

The effective care of dying patients requires a co-ordinated team approach. While many (72\%) respondents had received support from their peers, and half had been supported by their nursing colleagues, perhaps the most concerning finding from the questionnaire was that only II\% of respondents had received support from a consultant (or educational supervisor) during or after a patient death. Previous studies have shown that junior doctor discussions with consultants about patient death may happen frequently (74-76\% of patient deaths), but that these discussions are less often (24-35\%) perceived as supportive. ${ }^{30,31}$ Lack of support has been identified as an important theme of emotionally powerful deaths. ${ }^{7,14}$ Another possible consequence of this apparent lack of support is the fact that 19\% of respondents stated that they had had to sign an NFR form unsupervised. NHS Grampian resuscitation guidelines clearly state that NFR forms should (except in exceptional circumstances) be signed by the consultant or senior specialist registrar.

It has been noted in medicine that there is often a culture of not expressing emotions or seeking help, and 
as a result there is a hidden curriculum of 'educational neglect', where faculty do not discuss death or the emotional sequelae of looking after dying patients and their families. ${ }^{11,15,31}$ Such negative role modelling will potentially have a number of knock-on effects. Stressed and overwhelmed junior staff will be given the impression that there is something wrong with them ('how a death [that] doesn't seem to affect some other doctors makes you question your ability') and that they are not allowed to (and possibly don't know how to) get appropriate help and support. Patient care will suffer as junior staff are left with inappropriate responsibilities, such as signing NFR forms, without adequate and constructive supervision. Finally, these unsupported junior staff are likely to become unsupportive senior staff. ${ }^{32}$

Using a questionnaire to explore junior doctor experiences had a number of limitations. The format of a questionnaire lends itself to the gathering of quantitative data. Qualitative data about the range and depth of experiences will usually not be caught. Free text responses were sought, but unsurprisingly most respondents did not provide them. Obviously a semistructured, tape-recorded interview could have overcome these problems, but this process is very timeand labour-intensive and dependent on the skills of the interviewer. A further potential limitation of this study is respondent bias. It is conceivable that only the junior doctors who had particular types of experience considered returning the questionnaire. The results would not then be generalisable and, while a $56 \%$ response rate is quite high for a postal survey, almost half of the potential respondents are not represented.

From the questionnaire and literature review several areas are highlighted as important for any educational/ support intervention:

- Communication (end-of-life, including breaking bad news, NFR discussions and dealing with strong emotions):

- patients

- families (including bereaved)

- staff (in particular with consultants)

- Legal and ethical issues surrounding end-of-life care: - NFR

o treatment withdrawal

- Understanding the impact of one's own emotions and stress on the ability to practice effectively

- Knowing how and when to seek help and support

It is interesting to note that these needs relate more to emotional, analytical and personal competencies than to cognitive or technical competencies. This accurately reflects the reality of end-of-life care, where the 'technical' interventional facets of medicine are of minimal importance..$^{33}$ Quality of life in advanced disease has repeatedly been shown to be independent of markers of disease severity. ${ }^{34-36}$ This reduces the importance of the traditional medical history, examination, investigations and treatments - quality of life does not fit well into biomedical constructs of disease. More important appears to be the attitude of care, particularly promoting patient-centredness. ${ }^{8,37,38}$

The AMRC (2007) Foundation Programme curriculum ${ }^{23}$ focuses on acute care, particularly the management of the acutely ill patient. There is therefore a significant emphasis on technical and clinical competencies. This study has shown that junior doctors encounter end-oflife care situations frequently and that these situations are often distressing, requiring the development of emotional and personal competencies.

Careful thought will need to be given to the educational strategies used to address these needs. In the north of Scotland a small-group case-based teaching session has been developed for FYI doctors. This session addresses prognostication, illness trajectories and end-of-life care (symptom control, treatment withdrawal). More importantly, the facilitated small-group approach helps promote peer support and allows the junior doctors to explore ways of dealing with difficult situations in a safe environment. There remain concerns about how effectively this learning will transfer into the clinical environment.

Learning is context dependent and the influence (both positive and negative) of role modelling in these situations cannot be over-emphasisied. ${ }^{19}$ It is therefore important that clinical and educational supervisors are aware of the issues highlighted by this study - particularly that patient death can be emotionally distressing for junior doctors, that consultants need to ensure that they explain their treatment intent to their junior staff, and that junior staff who are struggling may well have had a recent significant personal bereavement. To deal effectively with these issues consultants may themselves need access to training and support. Changing working patterns for junior doctors, particularly in response to the European Working Time Directive, provide further challenges to consultants trying to provide continuity of supervision and support.

Future research could focus on the education and support needs of consultants responsible for junior doctors looking after dying patients. The issues of lack of support and perceived under/overtreatment could be further analysed through interviews with both junior doctors and consultants. Finally, a similar questionnaire could be administered to newly qualified nursing staff. It would be interesting to compare their experiences with those of junior doctors and explore whether interdisciplinary support/education would be useful.

Acknowledgements I would like to thank my educational supervisors, Dr Susan Law and Dr Gordon Watson, and my colleague Dr Sally Lawton, for their encouragement and helpful advice. 


\section{REFERENCES}

I Scottish Government. Living and dying well: a national action plan for palliative and end of life care in Scotland. Edinburgh: Scottish Government; 2008.

2 Department of Health. End of life care strategy - promoting high quality of care for all adults at the end of life. London: Department of Health; 2008.

3 NHS Grampian. Estimating unmet need for palliative care service provision in Grampian: palliative care needs assessment. Aberdeen: NHS Grampian; 2002.

4 Edmonds P, Karlsen S, Addington-Hall J. Palliative care needs of hospital inpatients. Palliat Med 2000; 14:227-8.

5 Firth-Cozens J. Emotional distress in junior house officers. BMJ 1987; 295:533-6. doi:10.1 136/bmj.295.6597.533

6 Firth-Cozens J, Morrison LA. Sources of stress and ways of coping in junior house officers. Stress Med 1989; 5:121-6. doi:10.1002/ smi.2460050210

7 Calman KC, Donaldson M. The pre-registration house officer year: a critical incident study. Med Educ 199I; 25:5I-9. doi:I0.1 III/j.1365-2923.199I.tb00026.x

8 MacLeod RD. On reflection: doctors learning to care for people who are dying. Soc Sci Med 200 ; 52:1719-27. doi:10.1016/S02779536(00)00289-6

9 Keizer B. My father's death. In: Bamforth I, editor. The body in the library: a literary anthology of modern medicine. London: Verso; 2003. p. 388.

10 Oliver D.Training and knowledge of palliative care of junior doctors. Palliat Med 1998; 12:297-9. doi:I0.I I9I/02692/69867502448I

II Sullivan AM, Lakoma MD, Block SD. The status of medical education in end-of-life care. A national report. J Gen Intern Med 2003; 18:685-95. doi:10.1046/j.1525-1497.2003.21215.x

12 Paice $E$, Rutter $H$,Wetherell $M$ et al. Stressful incidents, stress and coping strategies in the pre-registration house officer year. Med Educ 2002; 36:56-65. doi:10.1046/j.1365-2923.2002.0II0I.x

13 O'Neill PA, Jones A, Willis SC et al. Does a new undergraduate curriculum based on Tomorrow's Doctors prepare house officers for their first post? A qualitative study of the views of pre-registration house officers using critical incidents. Med Educ 2003; 37:1 100-8. doi:10.1046/j.1365-2923.2003.017/4.x

14 Jackson VA, Sullivan AM, Gadmer NM et al. 'It was haunting...' Physicians' descriptions of emotionally powerful patient deaths. Acad Med 2005; 80:648-56. doi:10.1097/0000/888-200507000-00007

15 Rhodes-Kropf J, Carmody SS, Seltzer D et al.'This is just too awful; I can't believe I just experienced that...': Medical students' reactions to their 'most memorable' patient death. Acad Med 2005; 80:634-40. doi:10.1097/00001888-200507000-00005

16 Orlander JD, Fincke G, Hermanns D et al. Medical residents' first clearly remembered experiences of giving bad news. J Gen Intern Med 2002; 17:825-31. doi:10.1046/j.1525-1497.2002.109/5.x

17 Sack WH, Fritz G, Krener PG et al. Death and the pediatric house officer revisited. Pediatrics 1984; 73:676-8I.

18 Paice E, Moss F, Heard S et al. The relationship between preregistration house officers and their consultants. Med Educ 2002; 36:26-34. doi:10.1046/j.I365-2923.2002.0II00.x

19 Fischer SM, Gozansky WS, Kutner JS et al. Palliative care education: an intervention to improve medical residents' knowledge and attitudes. J Palliat Med 2003; 6:39I-9. doi:10.1089/109662/03322/44709
20 Moores TS, Castle KL, Shaw KL et al. 'Memorable patient deaths': reactions of hospital doctors and their need for support. Med Educ 2007; 4I:942-6. doi:10.1 III/j.1365-2923.2007.02836.x

21 General Medical Council. The new doctor: recommendations on general clinical training. London: General Medical Council; 2009. Available from: http://www.gmc-uk.org/New_Doctor09_FINAL. pdf_snapshot.pdf

22 Academy of Medical Royal Colleges, Modernising Medical Careers. Curriculum for the foundation years in postgraduate education and training. London: Academy of Medical Royal Colleges, Modernising Medical Careers; 2005.

23 Academy of Medical Royal Colleges. Foundation Programme Curriculum. Academy of Medical Royal Colleges; 2007.

24 McAleer S. Designing a questionnaire. Educ Gen Pract 1994; 5:38-43.

25 Boynton P, Greenhalgh P. Selecting, designing and developing your questionnaire. BMJ 2004; 328:13/2-5. doi:10.1/36/bmj.328.745I.13/2

26 Heath I. Matters of life and death. Key writings. Oxford: Radcliffe Publishing; 2008. p. 19-24.

27 Scurry MT, Bruhn JG, Bunce $H$. The house officer and the dying patient. Gen Hosp Psych 1979; 1:301-5. doi:10.1016/01638343(79)90004-5

28 Sherry KL, Johnson MJ. An evaluation of hospice-based teaching in the west of Scotland. Palliat Med 1998; 12:467-8. doi:I0.1 I77/02692I63980I2006I3

29 Serwint JR. One method of coping: resident debriefing after the death of a patient. J Pediatr 2004; 145:229-34. doi:10.1016/j. ipeds.2004.04.055

30 Baverstock A, Finlay F. Specialist registrars' emotional responses to a patient's death. Arch Dis Child 2006; 91:774-6. doi:10.1136/ adc.2005.076760

31 Redinbaugh EM, Sullivan AM, Block SD et al. Doctors' emotional reactions to recent death of a patient: cross sectional study of hospital doctors. BMJ 2003; 327:185-91. doi:10.1 I36/bmj.327.7408.185

32 Davis BE, Nelson DB, Sahler OJ et al. Do clerkship experiences affect medical students' attitudes toward chronically ill patients? Acad Med 200I; 76:8I5-20. doi:10.1097/00001888-200108000-000I5

33 MacLeod RD, James CR. Improving the effectiveness of palliative care education. Palliat Med 1997; 11:375-80. doi:10.1 I77/02692163970II00507

34 Bromberg MB, Forshew DA. Comparison of instruments addressing quality of life in patients with ALS and their caregivers. Neurology 2002; 58:320-2.

35 Levack P, Graham J, Kidd J. Listen to the patient: quality of life of patients with recently diagnosed malignant cord compression in relation to their disability. Palliat Med 2004; 18:594-60I. doi: $10.1191 / 0269216304 \mathrm{pm} 9250 a$

36 Waldron D, O'Boyle CA, Kearney M et al. Quality-of-life measurement in advanced cancer: addressing the individual.J Clin Oncol 1999; 17:3603-II.

37 Olthuis G, Dekkers W. Medical education, palliative care and moral attitude: some objectives and future perspectives. Med Educ 2003; 37:928-33. doi:10.1046/j.1365-2923.2003.01635.x

38 Linklater GT. Promoting patient-centredness in undergraduate palliative care education. Med Educ 2008; 42:I I26-7. doi:I0.1IIII/ j.1365-2923.2008.03216.x 